\title{
Analysis of repeat LSCS in a tertiary care centre
}

\author{
M. Poovathi ${ }^{1 *}$, Suilharsini T. S. ${ }^{2}$ \\ ${ }^{1}$ Department of Obstetrics and Gynecology, Government Pudukkottai Medical College, Pudukkottai, Tamil Nadu, \\ India \\ ${ }^{2}$ Department of Obstetrics and Gynecology, KAPV Government Medical College, Trichy, Tamil Nadu, India
}

Received: 23 February 2018

Accepted: 28 March 2018

*Correspondence:

Dr. M. Poovathi,

E-mail: drmpoovathi@gmail.com

Copyright: () the author(s), publisher and licensee Medip Academy. This is an open-access article distributed under the terms of the Creative Commons Attribution Non-Commercial License, which permits unrestricted non-commercial use, distribution, and reproduction in any medium, provided the original work is properly cited.

\begin{abstract}
Background: Caesarean section (CS) rates continue to increase worldwide, particularly in middle and high-income countries without evidence indicating substantial maternal and perinatal benefits from the increase and some studies showing negative consequences for maternal and neonatal health. The objective of this study is to analyse the repeat caesarean section rates in a tertiary centre.

Methods: This is a retrospective study carried out in the Department of Obstetrics and Gynaecology, Pudhukottai Medical College, Tamil Nadu, India for a 12-month period from January 2017 to December 2017 with the aim to analyse the rate and indications for caesarean section and to identify the measures to decrease its incidence if possible. A total of 2654 cesarean deliveries were conducted in one year, out of which $1380(51.99 \%)$ were primary cesarean sections and 1274(48\%) were repeat cesarean sections.

Results: Repeat LSCS is more common in age group of 21-30 years (80\%) and in second gravida (90.42\%). The incidence of caesarean section is $94.6 \%$. Patients who had successful trial of scar were 73 . In all these patients, measures were taken to shorten the $2^{\text {nd }}$ stage of labour either by giving episiotomy alone or by application of outlet forceps or vacuum. Out of these $62(84.9 \%)$ patients were delivered by episiotomy alone.

Conclusions: Caesarean section has become one of the commonly performed surgeries in obstetric practice. Implementation of standard labour management strategies can reduce primary caesarean section rate without compromising maternal and fetal safety. One important strategy is ROBSON ' $\mathrm{S} 10$ GROUP classification system for caesarean section needs to be adopted. Targets of care needs to be set up which also depends on the available resources and expertise. With continuous critical review as described and frequent comparison with other delivery units, the caesarean section rate in each individual unit can be reduced to an appropriate level.
\end{abstract}

Keywords: Caesarean section, LSCS, Repeat LSCS, VBAC

\section{INTRODUCTION}

Caesarean section (CS) rates continue to increase worldwide, particularly in middle and high income countries without evidence indicating substantial maternal and perinatal benefits from the increase and some studies showing negative consequences for maternal and neonatal health. ${ }^{1}$ Caesarean section is one of the most common surgeries performed in modern obstetrics. $^{2}$ Developing countries like India are faced to the challenge of making the best use possible of limited resources to improve the health of women and children. Obstetrical intervention should be evidence based as mortality and morbidity due to unnecessary intervention could be hazardous. The rising trend of caesarean section in modern obstetrics is a major concern in health care 
system all over the world. With all the limited health care resources in a developing country like India, this rising trend definitely has major implication. ${ }^{1}$ According to WHO, rates of caesarean section in many countries have increased beyond the recommended level of $15 \%$, almost doubling in the last decade especially in high income areas like Australia, France, Germany, Italy, North America and United Kingdom. ${ }^{1}$ Similar trend is also seen in low resource countries like China, Brazil and India, especially due to births in private hospitals.

Even though the indication of CS has not changed so far, and these remain fetal distress, malpresentation, multiple gestation, previous caesarean, protracted labour and CS on demand. Current available data from developed countries revealed morbidity and mortality from $\mathrm{CS}$ is more than in vaginal delivery for both the mother and fetus. ${ }^{1}$

Thus, this study was conducted to evaluate the rate and indication for CS and to identify the measures to decrease its incidence if possible.

\section{METHODS}

This study was carried out in the Department of Obstetrics and Gynaecology, Pudhukottai Medical College, Tamil Nadu, India for a 12-month period from January 2017 to December 2017 with the aim to analyse the rate and indications for caesarean section.

\section{Inclusion criteria}

All patients with history of previous cesarean section were included in this study after getting Informed consent

\section{Exclusion criteria}

- History of uterine rupture

- Hysterotomy or previous uterine surgery (e.g. myomectomy)

- Previous caesarean section scar other than lower segment transverse incision (i.e. classical incision, T shaped incision or lower segment vertical incision)

- Any on medical complications like (hypertension, diabetes mellitus, anaemia, heart disease)

- Fetal anomaly which can lead to mechanical difficulty at birth.

2654 cases were selected after applying inclusion and exclusion criteria. Detailed history including their demographic details were taken. Thorough general and systemic examination is carried out. Obstetric examination is done to note-gestational age ( $\mathrm{SFH}, \mathrm{AG}$ ), Lie, presentation, presenting part, position of fetus and engagement of presenting part is noted. FHS is noted for rate and rhythm. Scar is visualized for, type (vertical or transverse), thickness (whether healed by secondary intention) and palpated for tenderness. Per vaginal examination under all aseptic precautions is done only if patient is in labour to note the cervical dilatation, effacement, condition of membrane and station of presenting part. At the same time pelvis is assessed for its shape, size and adequacy. If the head is floating assessment of CPD is done by Muller Kerr method in a patient who is at or near term. Necessary relevant lab investigations are carried out. USG is done in all cases to assess maturity of fetus, amount of liquor, location of placenta and thickness of scar.

Study group were divided into 2 parts

\section{Patients requiring elective/emergency LSCS}

Following were the criteria for selecting the patients for repeat caesarean

- More than 1 previous cesarean section

- Malpresentation and malposition

- Presence of scar tenderness

- Presence of any other obstetric complication (PROM, fetal distress, or any other high-risk factor)

- Scar healed by secondary intention.

Patient requiring repeat caesarean were admitted in ward. Out of this group patients who had/developed scar tenderness, fetal distress or labour pains, had to be taken up for emergency caesarean section.

\section{Patients who can be allowed for trial of vaginal birth ( $\mathrm{VBAC})$}

- Ability to perform emergency C-section

- No history of previous uterine rupture

- Maximum of 2 previous CS

- Clinically adequate pelvis

- Vertex fetal presentation

- No other uterine scars

- No CPD

- Intra and Post-operative period of previous cesarean section is smooth and without any complications

\section{RESULTS}

A total of 2654 cesarean deliveries were conducted in one year, out of which $1380(51.99 \%)$ were primary cesarean sections and 1274 (48\%) were repeat cesarean sections (Table 1). Repeat LSCS is more common in age group of 21-30yrs (80\%) (Table 2) and in second gravida $(90.42 \%)$ (Table 3). The incidence of caesarean section is $94.6 \%$ (Table 4) and the various indications of CS were shown in Table 5.

Patients who had successful trial of scar were 73. In all these patients measures were taken to shorten the $2^{\text {nd }}$ stage of labour either by giving episiotomy alone or by application of outlet forceps or vacuum. Out of these 62 
(84.9\%) patients were delivered by episiotomy alone (Table 6).

Rates of caesarean section in many countries have increased beyond the recommended level. Repeat LSCS rate is higher due to trend towards less trial of labour and early decision of repeat LSCS. In the present study repeat LSCS acounts for $48 \%$ of the total cesarean sections.

Table 1: Types of caesarean section.

\begin{tabular}{|ll|}
\hline Types & Number (percentage) \\
\hline Primary & $1380(51.99)$ \\
\hline Repeat & $1274(48)$ \\
\hline Total & 2654 \\
\hline
\end{tabular}

Analysis of age of the patients in the present study showed that most of the cases were in the age group of maximum fertility i.e. between $21-30$ years $(80 \%)$.

Table 2: Age distribution of previous LSCS patients.

\begin{tabular}{|l|l|l|}
\hline Age group (in years) & $\begin{array}{l}\text { No. of } \\
\text { patients }\end{array}$ & Percentage \\
\hline $21-25$ & 510 & 40 \\
\hline 2630 & 510 & 40 \\
\hline $31-35$ & 204 & 16 \\
\hline$>35$ & 50 & 4 \\
\hline
\end{tabular}

Maximum number of patients $90.42 \%$ were para 2, compared to just $9.58 \%$ patient falling in higher parity. This probably is due to trend of "small family norm."

Table 3: Parity distribution among repeat LSCS patients.

\begin{tabular}{|lll|}
\hline Parity & Number & Percentage \\
\hline Para-2 & 1152 & 90.42 \\
\hline Para-3 & 108 & 8.4 \\
\hline Para-4 & 14 & 1.18 \\
\hline
\end{tabular}

In present study patients were selected for trial of scar after applying ACOG criteria for trial of scar.

Of the 1347 women, 1274 (94.6\%) had elective repeat CS, 73 (5.4\%) had VBAC. Among 73 successful vaginal deliveries, 64 women had spontaneous vaginal delivery while 9 had assisted delivery with ventouse in order to cut short the second stage of labour.

Table 4: VBAC versus Repeat LSCS.

\begin{tabular}{|lll|}
\hline Repeat LSCS & Number & Percentage \\
\hline VBAC & 1274 & 94.6 \\
\hline $\begin{array}{l}\text { Total number of } \\
\text { previous LSCS patients }\end{array}$ & 73 & 5.4 \\
\hline
\end{tabular}

Table 5: Indications of present CS in a previous LSCS patient.

\begin{tabular}{|lll|}
\hline $\begin{array}{l}\text { Indications of present CS } \\
\text { indication }\end{array}$ & No. & Percentage \\
\hline Previous LSCS with CPD & 637 & 50 \\
\hline Previous 2 CS & 128 & 10 \\
\hline Fetal distress & 254 & 20 \\
\hline Malpresentation & 10 & 0.8 \\
\hline Oligohydramnios & 26 & 2 \\
\hline PIH & 32 & 2.5 \\
\hline Caesarean section on demand & 64 & 5 \\
\hline Twins & 19 & 1.5 \\
\hline Abruptio placenta & 102 & 8 \\
\hline Scar tenderness & 51 & 4 \\
\hline APH & 51 & 4 \\
\hline
\end{tabular}

In the present study the commonest reason for elective repeat LSCS was cephalopelvic disproportion: 637 $(50 \%)$, followed by fetal distress: 254 (20\%) and previous 2 cesarean section: $128(10 \%)$; least indication being malpresentation $10(0.8 \%)$ and multiple pregnancy $19(1.5 \%)$.

Table 6: Mode of delivery in successful trial of scar.

\begin{tabular}{|lll|}
\hline Mode of delivery & Number $(\mathbf{n}=73)$ & Percentage \\
\hline $\begin{array}{l}\text { Vaginal delivery } \\
\text { with episiotomy }\end{array}$ & 62 & 84.9 \\
\hline Forceps & 2 & 2.7 \\
\hline Vacuum & 9 & 12.3 \\
\hline Total & 73 & 100 \\
\hline
\end{tabular}

Patients who had successful trial of scar were 73. In all these patients, measures were taken to shorten the $2^{\text {nd }}$ stage of labour either by giving episiotomy alone or by application of outlet forceps or vacuum. Out of these 62 $(84.9 \%)$ patients were delivered by episiotomy alone. 2 (2.7\%) patients outlet forceps were applied. In 9 patients $(12.3 \%)$ vacuum was applied.

Table 7: Indication of previous cesarean section and outcome of labour.

\begin{tabular}{|llllll|}
\hline $\begin{array}{l}\text { Indication of } \\
\text { previous LSCS }\end{array}$ & $\begin{array}{l}\text { Total } \\
\text { No. }\end{array}$ & \multicolumn{2}{c|}{$\begin{array}{l}\text { Vaginal } \\
\text { delivery }\end{array}$} & \multicolumn{2}{c|}{$\begin{array}{l}\text { Repeat } \\
\text { LSCS }\end{array}$} \\
\hline Recurrent & 765 & - & - & 765 & $100 \%$ \\
\hline Nonrecurrent & 582 & 73 & $13 \%$ & 509 & $87 \%$ \\
\hline
\end{tabular}

In present study patients who had recurrent indication for previous CS were directly selected for repeat caesarean $765(100 \%)$. Patients who had non-recurrent indication for previous caesarean section were divided into 2 groups out of which group for trial of scar was selected after applying ACOG 2004 criteria for VBAC, out of which 73 (13\%) patients had successful VBAC. In $509(87 \%)$ patients there was failure of trial were taken for emergency repeat $\mathrm{CS}$. 


\section{DISCUSSION}

The present study is conducted in a tertiary care hospital. As such, most of the cases attending the OPD and also those availing the emergency services are basically referred cases from the nearby and also some of the distant PHC (Primary Health Centre), CHC (Community Health Centre), Sub divisional Dispensaries and the Civil Hospitals. Given the situation, it may be difficult to curtail the rates in tertiary care institutes, catering to a large population of referred cases. The reasons for the increased caesarean are multifaceted. ${ }^{1}$ Commonly causes includes Increased institutional deliveries, avoiding difficult manipulative or instrumental vaginal deliveries, fetal distress detected especially with the use of advanced technologies, liberal use of caesarean in high risk cases like Breech presentation, previous caesarean delivery, multiple pregnancy, preterm baby, improved safety of Csection with better surgical techniques, anaesthesia, better availability of blood and its products, advanced antibiotics and apprehension of the obstetrician regarding the fear of poor neonatal outcome. ${ }^{1}$

It is also possible that caesarean section rates were overestimated since vaginal deliveries at home may have been under reported. Strategies for reducing caesarean section have been framed and one such important strategy is ROBSON 'S 10 GROUP classification system for caesarean section. ${ }^{1}$ In 2011, a systematic review of available classifications for CS concluded that the Robson classification (also called the 10-group classification) would be in the best position to fulfil this gap $^{i}$. This system that classifies women into 10 groups based on their obstetric characteristics (parity, previous $\mathrm{CS}$, gestational age, onset of labour, fetal presentation and the number of fetuses). Since the system can be applied prospectively and its categories are totally inclusive and mutually exclusive, every woman that is admitted for delivery can be immediately classified based on these few basic characteristics which are usually routinely collected worldwide in obstetric wards. ${ }^{2}$

The methods that are required to do this successfully depends on implementation of the labour ward audit cycle-auditing the labour ward events and outcome, classifying them, assessing them, and subsequently modifying the management. Active participation of all the labour ward professionals is needed for collecting the information. Targets of care needs to be set up which also depends on the available resources and expertise. Regular multidisciplinary meetings are required, and the best way is daily morning labour ward meetings lasting for atleast half an hour wherein discussion of relevant events in the previous 24 hours need to be done. ${ }^{2}$

With continuous critical review as described and frequent comparison with other delivery units, the caesarean section rate in each individual unit can be reduced to an appropriate level.

\section{CONCLUSION}

The use of CS worldwide has increased to unprecedented levels although the gap between higher- and lowerresource settings remains. Caesarean section has become one of the commonly performed surgeries in obstetric practice. Implementation of standard labour management strategies can reduce primary caesarean section rate without compromising maternal and fetal safety. One important strategy is ROBSON 'S 10 GROUP classification system for caesarean section needs to be adopted. Targets of care needs to be set up which also depends on the available resources and expertise. With continuous critical review as described and frequent comparison with other delivery units, the caesarean section rate in each individual unit can be reduced to an appropriate level.

\section{ACKNOWLEDGMENTS}

Authors gratefully acknowledge and express their sincere thanks to their Dean, Government Pudukkottai Medical College and Hospital, Pudukkottai for allowing the authors to do this study and utilizing the Institutional facilities. Authors would also like to thank all the medical and para-medical staffs who have helped them to complete this study. Authors would specially like to thank all the patients who willingly co-operated and participated in this study. Authors also thank all their colleagues and friends who have been a constant source of encouragement to them. Authors also thank Dr. Sudharsini who has helped them in preparing this study.

Funding: No funding sources

Conflict of interest: None declared

Ethical approval: The study was approved by the Institutional Ethics Committee

\section{REFERENCES}

1. American College of Obstetricians and Gynecologists. Vaginal birth after previous cesarean delivery. ACOG Practice Bulletin No. 115. Obstet Gynecol. 2010;116:450-63.

2. Declercq E, Menacker F, Macdorman M. Maternal risk profiles and the primary cesarean rate in the United States, 1991-2002. Am J Public Health. 2006;96:867-72.

3. Declercq E, Menacker F, MacDorman M. Rise in "no indicated risk" primary caesareans in the United States, 1991-2001: cross sectional analysis. BMJ. 2005;330:71-2.

4. Rhodes JC, Schoendorf KC, Parker JD. Contribution of excess weight gain during pregnancy and macrosomia to the cesarean delivery rate, 1990-2000. Pediatr. 2003;111:1181-5.

5. Reddy UM, Ko CW, Willinger M. Maternal age and the risk of stillbirth throughout pregnancy in the United States. Am J Obstet Gynecol. 2006;195:76470 . 
6. MacDorman MF, Menacker F, Declercq E. Cesarean birth in the United States: epidemiology, trends, and outcomes. Clin Perinatol. 2008;35:293-307.

7. Menacker F, Declercq E, Macdorman MF. Cesarean delivery: background, trends, and epidemiology. Semin Perinatol. 2006;30:235-41.

8. Denk CE, Kruse LK, Jain NJ. Surveillance of cesarean section deliveries, New Jersey, 1999-2004. Birth. 2006;33:203-9.

9. Osterman MJ, Martin JA, Menacker F. Expanded health data from the new birth certificate, 2006. Natl Vital Stat Rep. 2009;58:1-24.
10. Gossman GL, Joesch JM, Tanfer K. Trends in maternal request cesarean delivery from 1991 to 2004. Obstet Gynecol. 2006;108:1506-16.

11. Centers for Disease Control and Prevention. Vaginal birth after cesarean birth-California, 1996-2000. MMWR Morb Mortal Wkly Rep. 2002;51:996-8.

Cite this article as: Poovathi M, Suilharsini TS Analysis of repeat LSCS in a tertiary care centre. Int J Reprod Contracept Obstet Gynecol 2018;7:1963-7. 